БАРИШОВЕЦ Екатерина Михайловна - аспирант Московского государственного университета им. М.В. Ломоносова (119991, Россия, г. Москва, Ломоносовский пp-кm, 27, корn. 4; barishovec@ gmail.com)

\title{
ИДЕАЛЬНЫЙ ПОРТРЕТ РУКОВОДИТЕЛЯ ОБРАЗОВАТЕЛЬНОГО КОМПЛЕКСА
}

Аннотация. Глобализация, будучи многосторонним процессом интеграции основополагающих областей деятельности различных государств в унифицированную общемировую систему, оказала огромное влияние на все сферы деятельности государства. Попала под воздействие глобализации и сфера образования. Ориентируясь на Болонскую декларацию, личность ребенка, установку о непрерывном образовании, а также на возрастающую потребность в компетентностном подходе, государство приняло решение о необходимости создания образовательных комплексов. Для эффективного управления образовательными комплексами необходимо наличие сильного успешного лидера, обладающего расширенным набором знаний, умений и навыков. Чтобы понять, какие качества определяют эффективность работы руководителя в системе управления образовательным комплексом, необходимо создать его идеальный портрет.

Ключевые слова: образовательный комплекс, профессиональные компетенции, глобализация

$\mathrm{B}$ середине XX в. ускоренное развитие науки и техники привело к изменению условий жизни общества, усложнению социальной, производственной, информационной среды и переходу на новый этап развития [Рыбакова 2015: 117].

По мнению Р.Я. Серышева, одной из основных задач образовательных комплексов является оптимизация и структуризация их внутренних процессов, правильная постановка процессного управления и повсеместное внедрение системы мониторинга качества процессов и результатов деятельности [Серышев 2017: 175].

Любой управляющий должен обладать рядом навыков, знаний и качеств, чтобы успешно выполнять свою работу. М.П. Лаврищев в числе профессиональных компетенций, получивших широкое распространение, называет такие, как мобильность; знание иностранных языков и уважение к национальным особенностям, культуре и традициям зарубежных стран; технологическая грамотность; навык грамотного поиска и анализа информации, которая поступает извне организации, дальновидность и умение дозированно транслировать информацию во внешнюю среду; аналитический склад ума, способный в то же время проявлять креативный подход к трудовой деятельности, инновационный стиль мышления; верность принципам организации, социальная ответственность; способность к быстрой адаптации в соответствии с изменившимися условиями; стремление к получению новых знаний и саморазвитию, понимание и принятие концепции непрерывного образования, позволяющего быть в курсе появления и развития новых технологий в профессиональной сфере деятельности [Лаврищев 2013: 131].

Безусловно, все предложенные выше компетенции необходимы и специалисту образовательной сфере, который смог бы управлять образовательным комплексом.

Компетенции руководителя-управленца государственного учреждения, а конкретно - образовательного комплекса, демонстрируют конвергенцию мотивационной предрасположенности специалиста к взаимодействию с обществом и в то же время владение практическими способами решения огромного спектра задач, возникающих в сфере профессионального взаимодействия в данной системе. 
Немецкий социолог М. Вебер разработал концепцию «идеального типа». Согласно исследователю, продуктом теоретического социологического исследования, которое опирается на сопоставление эмпирических фактов социальноисторической деятельности и сравнительный анализ, является формирование представлений об идеальном типе социальных явлений [Вебер 1990: 389]. В то же время ученый оговаривает, что идеальный тип утопичен, его нельзя найти в повседневной реальности, и рассматривает его исключительно как логическую конструкцию для обработки полученных эмпирических данных.

Но, несмотря на утопическую природу идеальных типов, любой руководитель, если он нацелен на эффективную работу, будет всегда действовать в рамках данной концепции. Чтобы выяснить, какие качества на самом деле определяют эффективность работы руководителя в системе управления образовательным комплексом, и попробовать создать его идеальный портрет, было решено провести исследование.

Весной 2019 г. в группе педагогов государственных образовательных комплексов и родителей (законных представителей) обучающихся было проведено анкетирование. Выборка сплошная и составила 156 респондентов в первом случае и 167 - во втором.

Для сохранения объективности исследования были опрошены педагоги и родители, имеющие прямое отношение к образовательным комплексам, руководители которых приняли участие в интервьюировании. Беседы были призваны определить представление родителей и педагогов о компетенциях и качествах, как личных, так и профессиональных, которыми должен обладать руководитель образовательного комплекса.

В первой группе опрошенных (среди педагогов) большую часть респондентов составляют учителя-предметники и учителя младших классов $(57,2 \%$ и $19,7 \%$ соответственно). Помимо них, в опросе приняли участие педагоги-организаторы $(9,1 \%)$, психологи $(7 \%)$, логопеды $(2,1 \%)$ и другие сотрудники образовательных комплексов. Группа преподавателей в основном представлена молодыми специалистами в возрасте от 25 до 34 лет (46,8\%). Следующая по численности возрастная группа представлена опрошенными в возрасте от 45 до 54 лет $(21,2 \%)$. Педагоги от 35 до 44 лет составляют 15,4\%. Число преподавателей от 18 до 24 лет и старше 55 лет примерно равно (10,3\% и 10\% респондентов соответственно). Среди педагогов, принявших участие в анкетировании, число женщин заметно превышает число мужчин (85,9\% и 14,1\% соответственно).

Респондентам было предложено ответить на 3 тематических блока вопросов: общие вопросы, вопросы о профессиональных качествах руководителя, вопросы о личных качествах руководителя.

По итогам анкетирования педагогов можно сделать вывод, что у них существует сформировавшийся образ грамотного руководителя.

Возраст, пол, семейное положение и наличие степени не являются определяющими показателями для хорошего руководителя. Однако он должен иметь высшее образование и опыт работы как в педагогике, так и в области управления. Респонденты считают, что оптимальным вариантом является руководитель, имеющий два высших образования и хорошо разбирающийся не только в указанных областях, но и в психологии и юриспруденции. Первое обосновано тем, что он постоянно контактирует с людьми разного возраста и мировоззрения. Грамотный лидер должен уметь находить общий язык с каждым из них, понимать мотивы их поведения и уметь выносить справедливые решения.

Хороший руководитель обладает такими профессиональными качествами, как компетентность, стратегическое мышление, эффективная коммуникация и умение быстро действовать в экстремальных ситуациях. Для него характерны 
такие личные качества, как порядочность, ответственность, объективность, честность и стрессоустойчивость.

Кроме этого, руководитель должен обладать хорошими манерами, быть интеллигентным и обладать чувством меры. С его стороны недопустимы неформальные манеры поведения и грубая речь. Также часть респондентов отметили, что нежелательно наличие пирсинга или татуировок.

Аналогичная анкета была предложена группе родителей. В качестве респондентов выступили люди в возрасте от 24 до 55 лет. Большую часть из них составили родители в возрасте от 35 до 44 лет (67\%). Практически равные группы составили родители, возраст которых составил от 24 до 34 лет (16,2\%) и от 45 до 54 лет (15\%). Самой немногочисленной оказалась группа родителей старше 55 лет (1,8\%). Основную часть респондентов, принявших участие в данном исследовании, составляют женщины, что перекликается с предыдущим опросом (88\% женщин против 12\% мужчин).

По результатам опроса было выявлено, что пол, возраст или семейное положение руководителя с точки зрения родителей не играют ключевой роли в выполнении возложенных на него задач. Но желательно, чтобы у него были дети, а следовательно, имелся родительский опыт.

Если анализировать ответы родителей, касающиеся профессиональных качеств, то у руководителя должно быть как минимум одно высшее образование, предпочтительно педагогическое. Однако успешному управлению комплексом будет способствовать получение второго профильного образования (либо педагогического, либо в области управления). Обязателен соответствующий опыт работы. А вот наличие регалий обязательным фактором не является.

Среди желаемых профессиональных качеств родители назвали компетентность, эффективную коммуникацию и умение действовать в экстремальных ситуациях. В число важных качеств вошли умение выделять первоочередные цели и задачи, быстро находить решение, работать в команде, целеустремленность и решительность. Руководитель должен учитывать интересы ребенка и его родителей, хорошо разбираться в психологии, педагогике, социологии и менеджменте.

Родители также выделили такие личные качества руководителя, как ответственность, порядочность, честность, добросовестность и стрессоустойчивость, хорошие манеры, интеллигентность и аккуратность.

Рассмотрев образ руководителя образовательного комплекса с точки зрения родителей, можно сделать вывод, что их точка зрения во многом совпадает с мнением педагогов, что позволяет составить идеальный портрет руководителя образовательного комплекса.

В обоих случаях не принципиальны такие показатели, как пол, семейное положение и наличие ученой степени. Это не является показателем качества работы руководителя, а потому практически не рассматривается вне остального контекста.

В обоих случаях считается, что оптимально иметь второе высшее образование (управленческое либо педагогическое, в зависимости от первого) для более грамотного управления комплексом. Кроме этого, очень желательно иметь опыт работы в указанных областях.

Помимо менеджмента и педагогики, руководитель должен хорошо разбираться в психологии и, как считают родители, в социологии. С утверждением, что руководители должны в первую очередь учитывать интересы детей, согласны обе группы респондентов.

К важным для руководителя профессиональным качествам и педагоги, и родители отнесли компетентность, эффективную коммуникацию, умение дей- 
ствовать в экстремальных ситуациях. К деловым качествам - умение выявлять первоочередные задачи и быстро находить верное решение. Умение работать в команде является важным качеством как для руководителей, так и для педагогов, потому что в данном вопросе и те и другие являются участниками процесса. В число личных качеств вошли ответственность, порядочность, честность и стрессоустойчивость. При этом руководитель образовательного комплекса должен быть интеллигентным, аккуратным и обладать хорошими манерами.

\title{
Список литературы
}

Вебер М. 1990. Избранные произведения (пер. с нем. М.И. Левиной). М.: Прогресс. 804 с.

Лаврищев М.П. 2013. Формирование профессиональных компетенций менеджера в условиях глобализации. - Международный научно-исследовательский жмурнал. № 8(15). Ч. 3. С. 131-133.

Рыбакова М.В. 2015. Функциональная неграмотность как проявление кризиса образования. - Российский научный журнал. № 6(49). С. 117-121.

Серышев Р.В. 2017. Условия и тенденции развития системы управления образовательными комплексами и учреждениями. - Вестник ГУУ. № 4. С. 175-180.

BARISHOVETS Ekaterina Mikhailovna, postgraduate student at the Lomonosov Moscow State University (bld. 4, 27 Lomonosovsky Ave, Moscow, Russia, 119991; barishovec@gmail.com)

\section{PERFECT PORTRAIT OF THE HEAD OF THE EDUCATIONAL COMPLEX}

\begin{abstract}
Globalization as a multilateral process of integrating the fundamental areas of activity of various states into a unified global system has a tremendous impact on all areas of the government action. The sphere of education has also come under the influence of globalization. Focusing on the Bologna Declaration, the personality of the child, the orientation on continuing education, as well as on the growing need for a competency-based approach, the state decided upon the need to create educational complexes. Effective management of educational complexes requires a strong successful leader with a more expanded set of knowledge, skills. To understand what qualities determine the effectiveness of the leader in the educational management system, it is necessary to create the ideal portrait of the leader. Keywords: educational complex, professional competence, globalization
\end{abstract}

